\title{
Long term effects of the Latham presurgical maxillary orthopedic appliance, including effects on tooth growth
}

\author{
Michel C Samson MD ${ }^{1}$, Donald H Lalonde MD MSc FRCSC ${ }^{1}$, Donald Fitzpatrick DDS ${ }^{3}$, \\ Gerald L Sparkes MD FRCSC ${ }^{1}$ \\ ${ }^{I}$ Division of Plastic Surgery, Dalhousie University; ${ }^{2}$ Saint John Regional Hospital, Saint John, \\ New Brunswick; ${ }^{3}$ Isaac Walton Killam - Grace Children's Hospital, Halifax, Nova Scotia
}

\begin{abstract}
MC Samson, DH Lalonde, D Fitzpatrick, GL Sparkes. Long term effects of the Latham presurgical maxillary orthopedic appliance, including effects on tooth growth. Can J Plast Surg 2000;8(1):15-20.
\end{abstract}

Reported beneficial effects of presurgical maxillary orthopedics in cleft lip include reduction of the cleft width, alignment of the maxillary segments, elevation of the alar base on the cleft side, diminished need for alveolar bone grafting and lip closure without tension. Possible adverse effects of presurgical maxillary orthopedics include tooth root damage and inability of periosteoplasty to make bone over the cleft. A series of wide cleft lip patients $(n=15)$ treated with the Latham appliance at the time of lip closure were retrospectively compared with a similar group treated without the Latham appliance. The Latham appliance group (seven unilateral clefts, eight bilateral clefts; mean follow-up 9.5 years; range four to 18 years) was treated between the years 1980 and 1994 . None of the 15 patients treated with the appliance had any tooth loss or damage attributable to the pins, and bone formation in the alveolar cleft was observed radiographically in all 13 of the patients who had a periosteoplasty at the time of lip repair, possibly obviating the need for secondary bone grafting. Five of these Latham group patients demonstrated clinical and radiographic evidence of tooth eruption into the periosteoplasty-formed bone. There was no consistent difference in the level of nasal alar base elevation in the two groups.

Key Words: Cleft lip; Cleft palate, Latham appliance; Periosteoplasty; Presurgical maxillary orthopedics

Effets à long terme de l'appareil orthopédique maxillaire préchirurgical de Latham y compris sur la pousse des dents

RÉSUMÉ : Les effets bénéfiques rapportés au sujet d'un appareil orthopédique maxillaire sur la fissure labiale comprennent une réduction de la largeur de la fente, un alignement des segments maxillaires, une élévation de la base alaire sur le côté de la fissure, un besoin moindre de greffe d'os alvéolaire et la fermeture de la lèvre sans tension. Les effets indésirables potentiels d'un appareil orthopédique maxillaire préchirurgical comprennent des dommages aux racines et une incapacité de la périostéoplastie à fabriquer de l'os sur la fissure. Une série de patients présentant de larges fissures labiales $(n=15)$ et traités avec l'appareil de Latham au moment de la fermeture de la lèvre ont été comparés de façon rétrospective avec un groupe similaire traité sans l'appareil de Latham. Le groupe avec l'appareil de Latham (7 fissures unilatérales, 8 fissures bilatérales ; recul clinique moyen de 9,5 ans ; fourchette de 4 à 18 ans) a été traité entre les années 1980 et 1994. Aucun des 15 patients traités avec l'appareil n'a subi de perte de dents ou de dommages attribuables aux tiges, et l'ostéogenèse dans la fente alvéolaire a été observée par radiographie chez les 13 patients qui avaient subi une périostéoplastie au moment de la réparation de la lèvre, évitant ainsi le besoin de procéder à une greffe d'os secondaire. Cinq des patients du groupe avec l'appareil de Latham démontraient des preuves cliniques et radiologiques de pousse de dents dans l'os formé par périostéoplastie. Il n'y avait pas de différence significative dans le niveau de l'élévation de la base alaire nasale entre les deux groupes.

$\mathrm{M}$ axillary orthopedic appliances have gained significant popularity in the treatment of infants with cleft lip and palate in the past 20 years. The principal objective of presur-

This paper was presented at the 52nd Annual Meeting of the Canadian Society of Plastic Surgeons, May 20 to 24, 1998, Victoria, British Columbia

Correspondence: Dr Don Lalonde, 705 Millidge Avenue, Saint John, New Brunswick E2K 2N7. Telephone 506-648-7950, fax506-652-8042, email huzil@health.nb.ca gical maxillary orthopedics is to reduce the size of the cleft and stabilize the maxillary platform, thereby facilitating early lip surgery (1). This is particularly true for patients with wide clefts. A more normal maxillary arch form is thought to be attained with an orthopedic appliance, allowing proper positioning of the nasal base, closure of palatal fistulae, proper tooth alignment and growth, reduced need for alveolar bone grafting, easier secondary nasal and lip surgery, and positive psychological benefits $(2,3)$. However, preoperative ortho- 
pedics have been criticized as being harmful because they have been reported to restrict maxillary growth (4) and possibly injure tooth buds. However, the effect of these appliances on tooth development and tooth eruption through periosteoplasty-formed bone in the cleft has received little attention in the literature.

The purpose of the present study was to evaluate the long term outcome in a group of patients treated with the Latham presurgical maxillary orthopedic appliance. In particular, the ability of periosteoplasty to form bone able to erupt teeth across a cleft was assessed, and nasal alar base elevation and maxillary arch alignment were determined.

\section{PATIENTS AND METHODS}

All patients admitted to the Saint John Regional Hospital with a diagnosis of complete unilateral or bilateral cleft lip and palate between the years 1980 and 1994 were identified through the Patient Information Services Department of that hospital. The subset of this group of patients with wider clefts who were treated with the Latham presurgical maxillary orthopedic appliance was identified. Demographic information, operations performed, bone grafting required and orthodontic records were obtained. All patients available for review were examined.

A dental impression of the maxillary teeth was performed and correlated with the direct examination of maxillary arch form. Panorex radiographs of the maxilla and mandible were also obtained. Anthropometrical measurements of the level of alar base elevation were carried out directly. The patients' teeth and maxillary alveoli were carefully examined, both clinically and radiographically, by an orthodontist. Standardized photographs of the frontal, lateral and worm's eye view of the nose and midface were obtained. A second set of nasal alar base measurements were obtained from these photographs and correlated with the direct measurements.

A second group of complete cleft lip and palate patients treated in Halifax, Nova Scotia, without the Latham appliance was identified. An age- and cleft type-matched group was selected for comparison regarding the level of nasal alar base elevation and maxillary arch form. The patients were similarly examined and photographed. All hospital records were reviewed.

The treatment protocol for patients with wide unilateral or bilateral complete clefts treated in Saint John, New Brunswick was as follows.

1. Dental impressions were taken at two weeks, and the impressions were sent to Dr Ralph Latham in London, Ontario for custom fabrication of the appliances.

2. The appliances were inserted at six weeks and the maxillary arch segments manipulated until they were anatomically aligned and touching. This goal was achieved in 13 of the 15 Latham-treated patients. In two patients, the segments could not be brought together and periosteoplasty was not performed.

3. The appliances were removed, and periosteoplasty and primary lip repair were performed using the Millard rotation advancement technique at three to four months.

4. V-Y pushback palatoplasty with muscle sling repair was performed at nine to 12 months.

5. All patients were treated with orthodontics.

The treatment protocol for patients with wide unilateral or bilateral complete clefts treated in Halifax was as follows.

1. Primary lip repair was performed at two months using a modified Millard rotation advancement repair.

2. Primary alveolar bone grafting was performed at six to nine months.

3. V-Y pushback palatoplasty with muscular sling repair was performed at nine to 12 months.

4. All patients were treated with orthodontics.

Standard secondary procedures indicated in patients with cleft lip and palate were performed in a similar fashion in both groups.

\section{RESULTS}

At the Saint John Regional Hospital, 21 of the 27 clefts seen were wide enough to warrant the use of the Latham appliance between the years 1980 and 1994. Six of the patients were not treated with the Latham appliance because the clefts were not wide and the maxillary arches were already in anatomical position. The appliance was used on eight bilateral clefts and 13 unilateral complete clefts. Of these patients, 15 were available for review (seven unilateral clefts, eight bilateral clefts). Mean follow-up time was 9.5 years (range four to 18 years). Similar age- and cleft-matched groups were selected from the list of actively treated cleft patients at the IWK - Grace Hospital for Children in Halifax.

\section{Tooth status in the group treated with the Latham appliance}

All patients treated with the Latham appliance were carefully examined by an orthodontist for tooth damage attributable to the pins. One bilateral cleft patient had bilateral absence of the cuspids, but this was also present in the mandibular teeth and, therefore, thought to be a congenital anomaly. Another patient had an abnormal incisor tooth extracted that was away from the area of insertion of the stabilizing pins (usually first premolar to first molar teeth). Panorex radiographs were reviewed by the orthodontist; there were no signs of tooth root damage in any teeth. Clinical examination by the orthodontist revealed no tooth loss and no other physical signs of damage to the teeth attributable to the maxillary orthopedic device.

\section{Maxillary arch form}

The patients' physical examination of the arches was correlated with their dental impressions. The arch form examination gave a similar dental impression, and this information 


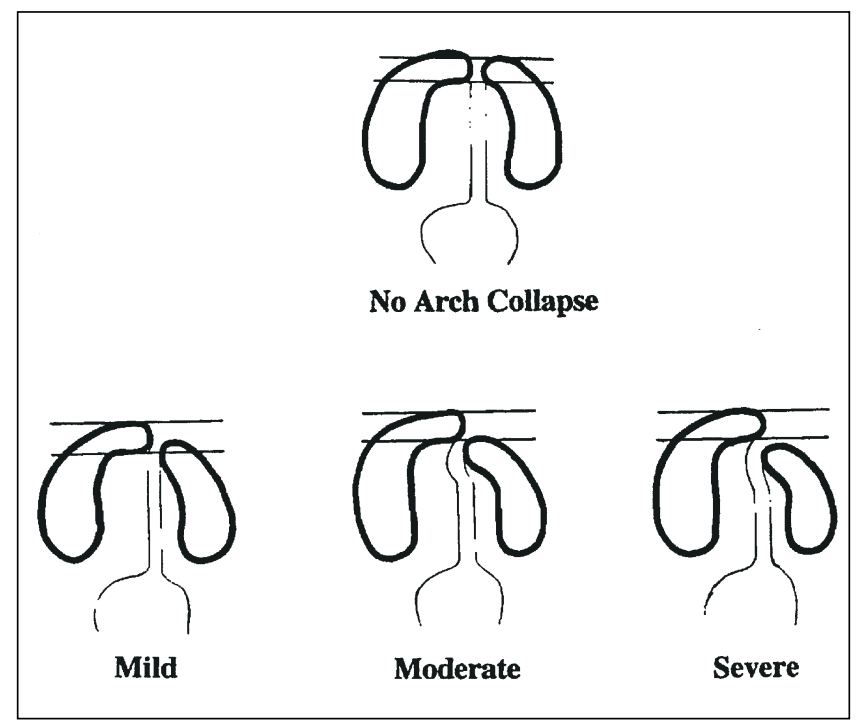

Figure 1) A classification of maxillary arch collapse, unilateral clefts

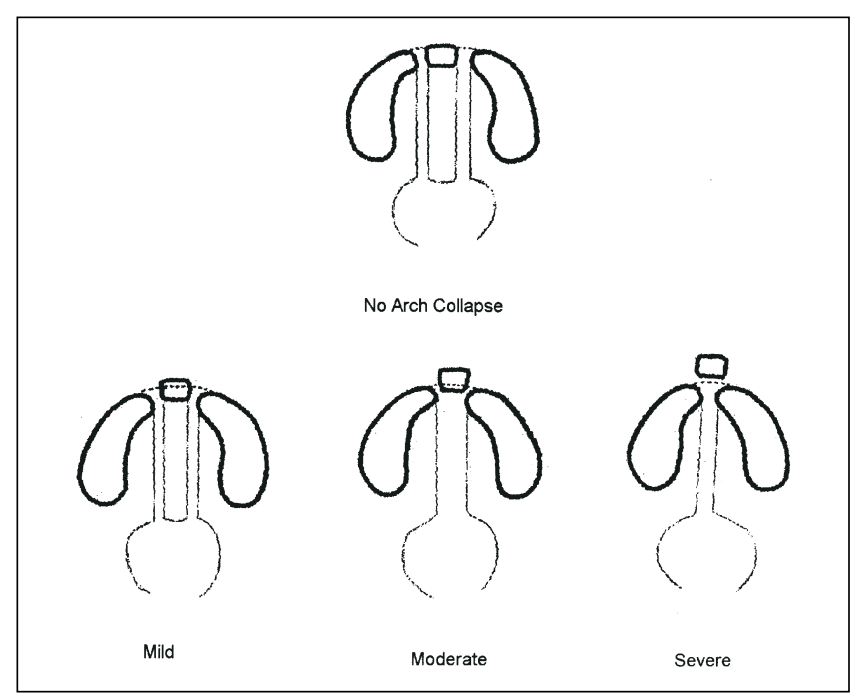

Figure 2) A classification of maxillary arch collapse, bilateral clefts

was used to classify the degree of arch collapse into mild, moderate and severe (Figures 1,2). There was a range of arch forms in both groups (Figures 3,4). There was no significant or consistent difference in long term outcome between the two groups of patients studied with respect to maxillary arch form.

\section{Nasal alar base elevation}

Nasal alar base measurements in both groups of patients were taken from the worm's eye view of the standardized photographs (Figures 5,6). These measurements were verified by direct measurement in all cases. At the time of follow-up, nine patients in each group had undergone one or more secondary rhinoplasty operations. There was no significant or consistent difference in long term outcome between the two groups of patients studied with respect to nasal alar base elevation (Figures 7,8).

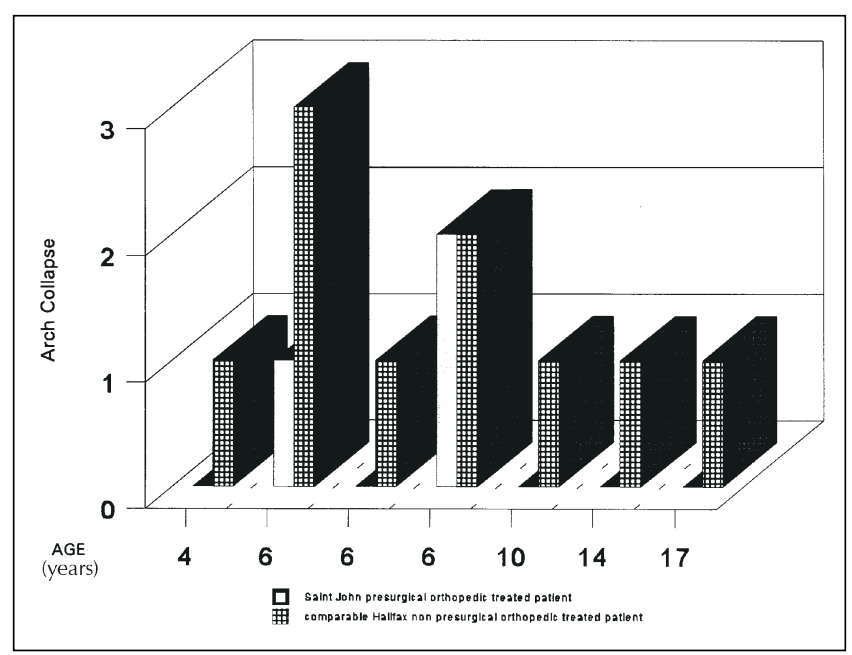

Figure 3) Maxillary arch form in unilateral clefts. 0 No collapse; 1 Mild collapse; 2 Moderate collapse; 3 Severe collapse

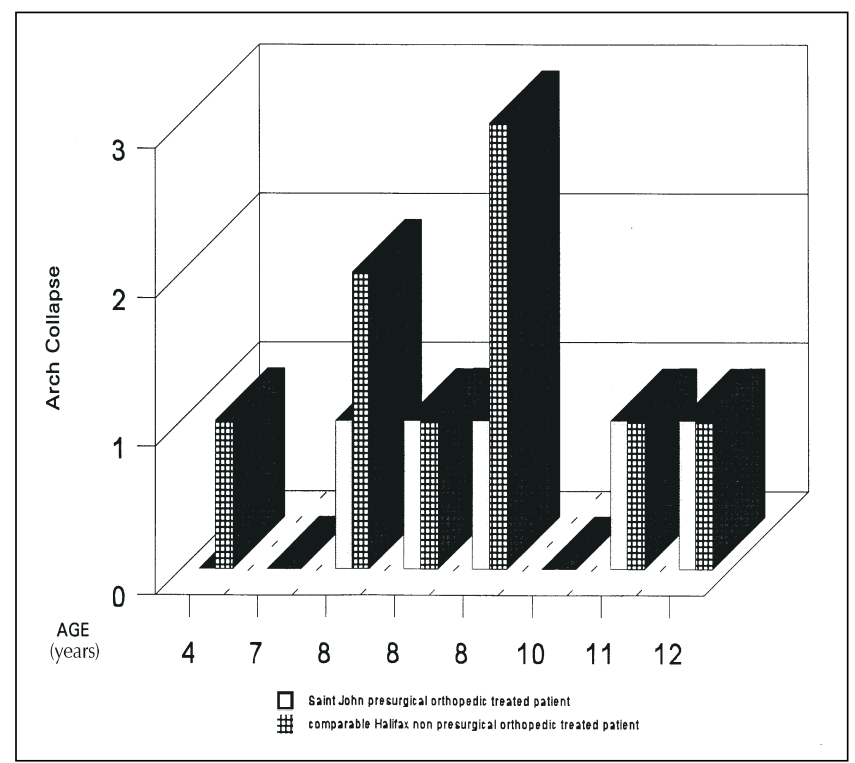

Figure 4) Maxillary arch form in bilateral clefts. 0 No collapse; 1 Mild collapse; 2 Moderate collapse; 3 Severe collapse

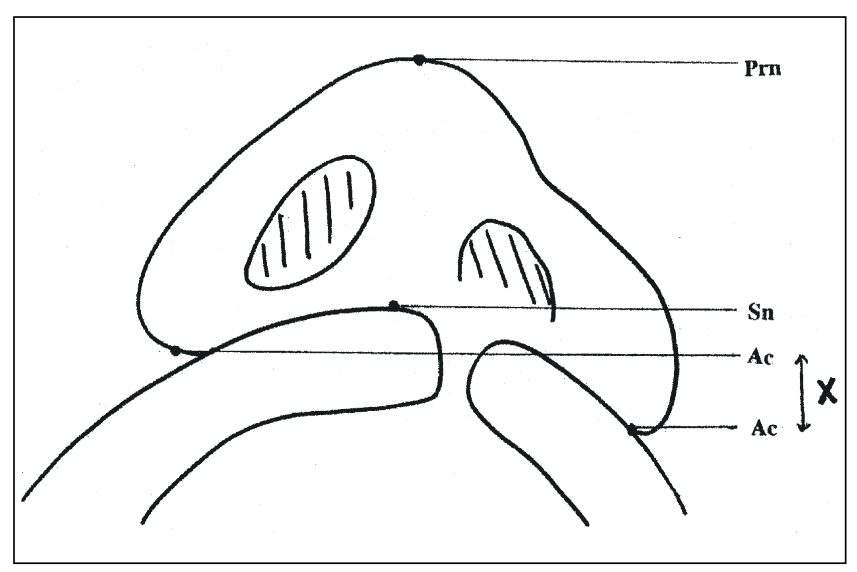

Figure 5) Measurement of nasal alar base elevation. Ac Alar crest point; Prn Pronasale; Sn Subnasale; X unilateral cleft 


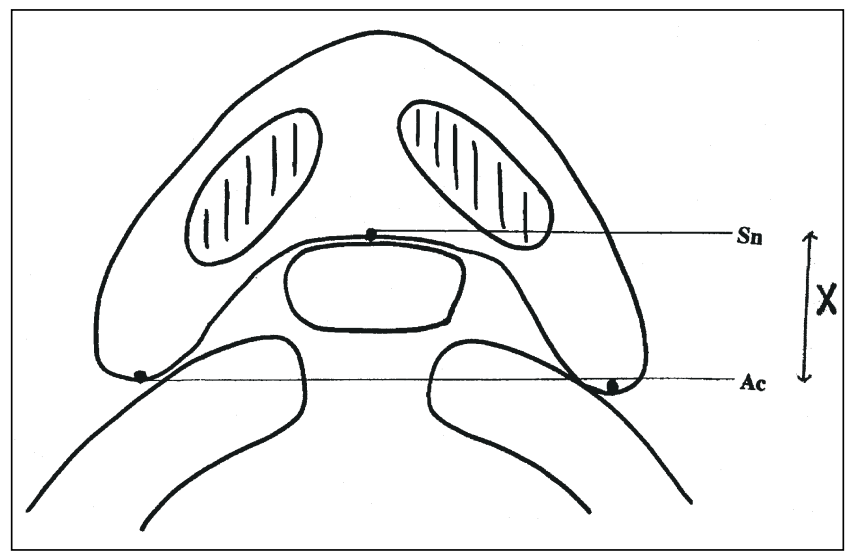

Figure 6) Measurement of nasal alar base elevation. Ac Alar crest point; Sn Subnasale; X unilateral cleft

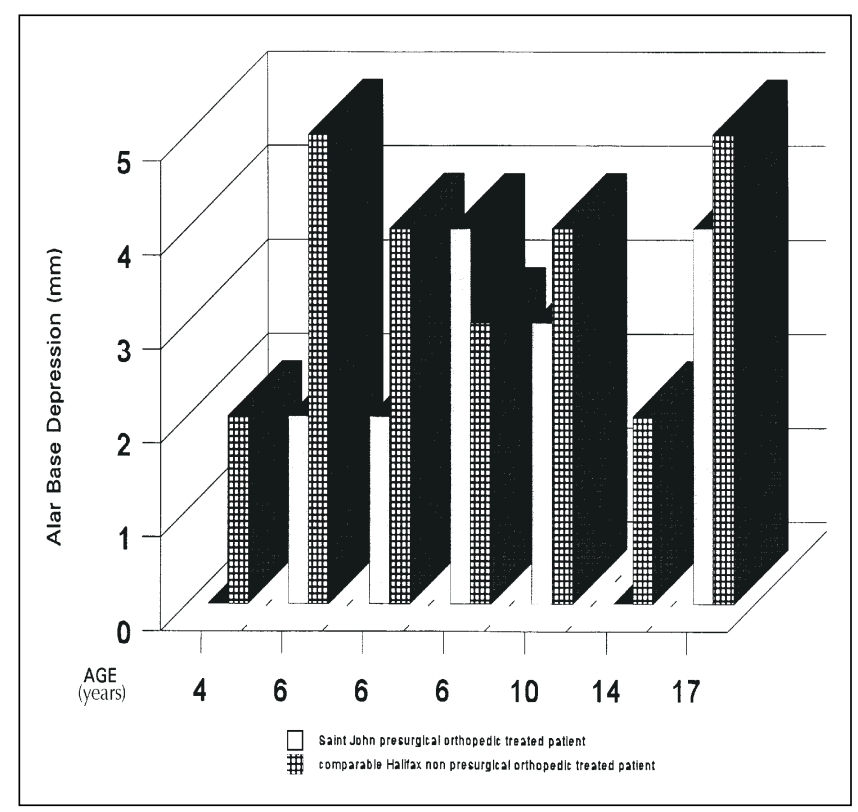

Figure 7) Nasal alar base depression in unilateral clefts

Bone formation and tooth migration in the alveolar cleft All patients in the Latham appliance group were evaluated using a panorex radiograph for bone formation in the alveolar cleft. This was done by using the normal interdental spaces as a reference comparison. Thirteen of the 15 orthopedic device-treated patients had evidence of bone formation in the periosteoplasty-lined cleft as evidenced by calcification of similar radiographic density and distribution as seen in the normal interdental spaces. These 13 patients with periosteoplasty-formed bone in the cleft did not require any bone grafting procedures to fill the alveolar cleft. The two patients who did not form bone in the cleft did not get a periosteoplasty at the time of lip repair because the appliance was unable to get the maxillary segments touching at the time of lip repair. Five of the 13 patients exhibiting bone formation had radiographic evidence of tooth eruption into the bone formed in the alveolar cleft. All patients who did not have a perma-

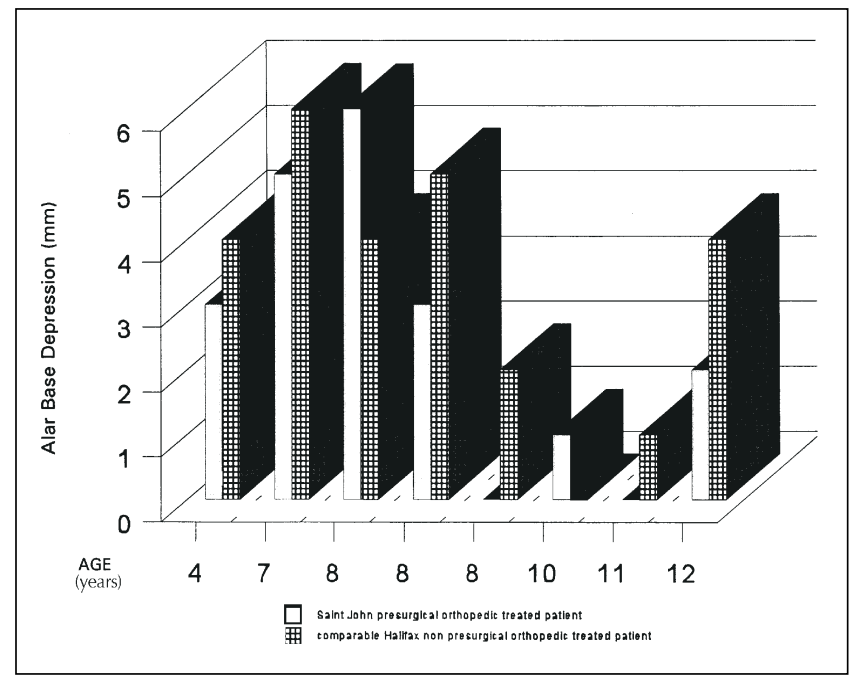

Figure 8) Nasal alar base depression in bilateral clefts

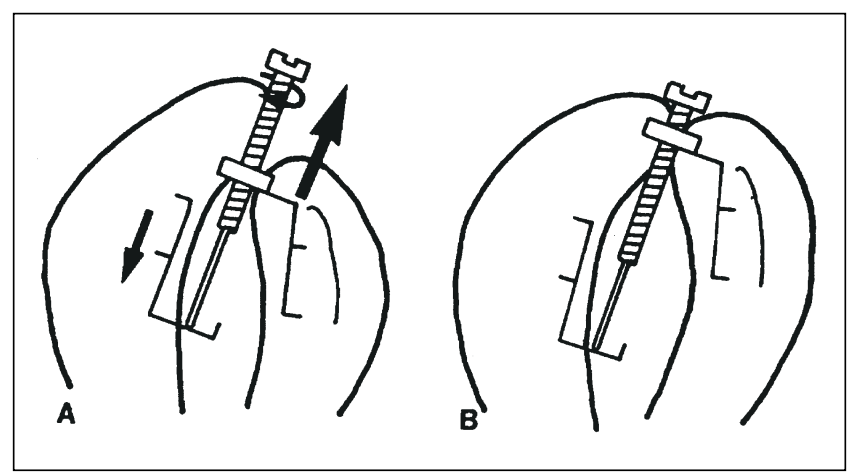

Figure 9) A Schematic diagram of the mechanics of the Latham appliance; B Gradual tightening of the screw closes the unilateral cleft. As the screw tightens, the cleft palatal arch moves forward (large arrow) and the noncleft palatal arch moves posteriorly (small arrow)

nent lateral incisor erupting through the cleft were too young (age six years and younger) to have a permanent tooth in. This was confirmed on clinical orthodontic examination of the teeth. In contrast, all patients in the non-Latham group had one or more bone grafting procedures performed.

\section{DISCUSSION}

Traditional treatment of wide unilateral and bilateral clefts consists of lip closure under tension, or a lip adhesion procedure followed by definitive lip repair as a secondary procedure, with bone grafting at a later date. In comparison with traditional techniques, the use of maxillary orthopedics undoubtedly brings the lip segments and maxillary arches to anatomical alignment and greatly facilitates the lip repair and periosteoplasty without the need for closure under tension or lip adhesion (5). The authors of this study and any others who have used this technique have seen this clearly.

Introduced over four decades ago by McNeil (6), these appliances have undergone numerous modifications in design. The Latham orthopedic appliance was initially described in 1976 (1). It is an intraoral active appliance custom-made on 


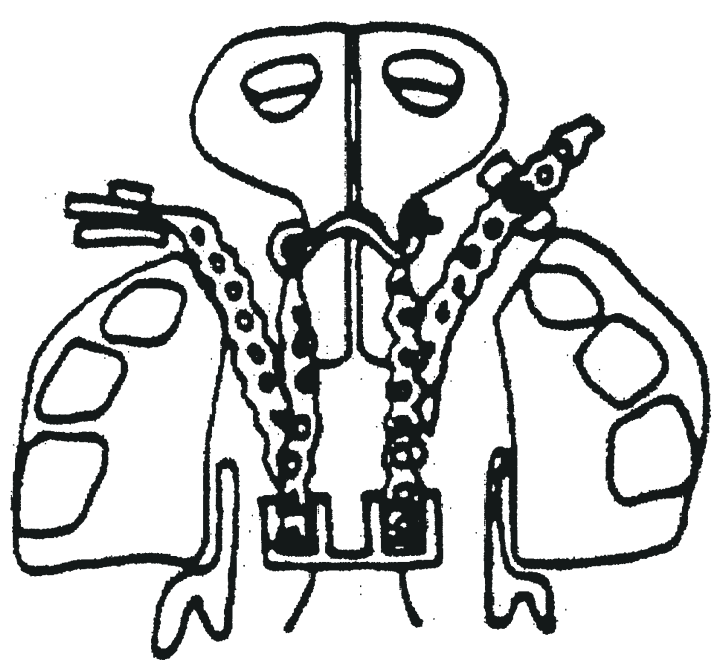

A

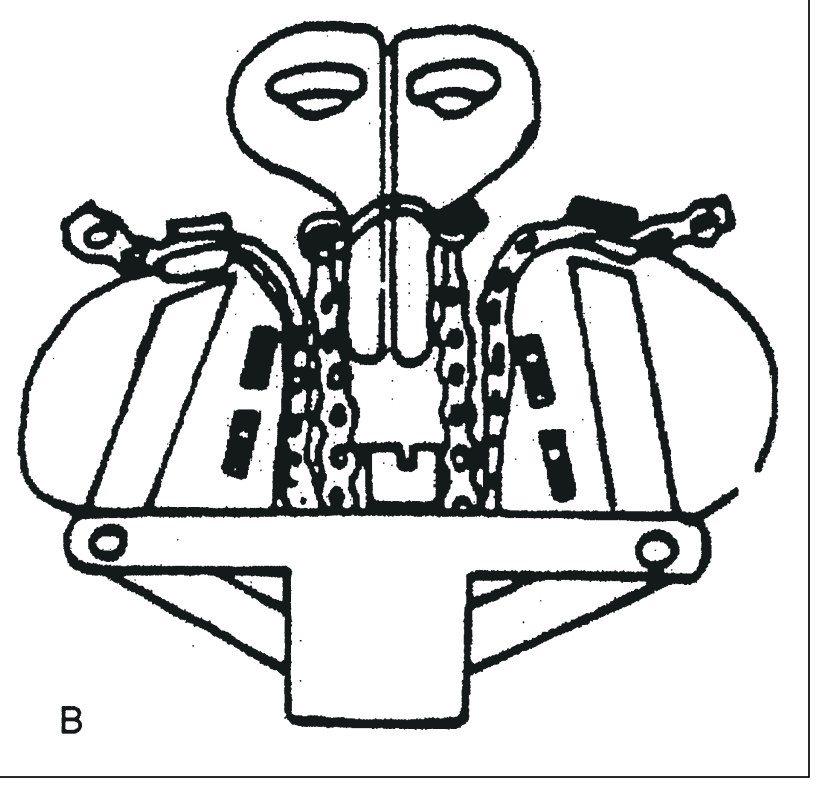

Figure 10) A Elastics applied to the premaxilla in bilateral cleft. B Latham appliance gradually brings the premaxilla back and widens the palatal shelves

the infant's plaster cast of the palate. It is fixed onto the palate by four $0.70 \mathrm{~mm}$ stainless steel pins on each side; a screw activated by the parent pushes and pulls the cleft segments into alignment over three to six weeks (Figures 9,10,11). When the maxillary arch is anatomically aligned, the appliance is removed and primary lip repair with gingivoperiosteoplasty is performed without tension. The appliance has not been universally adopted, however. Possible reasons include the effort, expense and need for coordinating treatment at an early age with a pediatric orthodontist.

There has been some concern raised over the potential deleterious effects of the pins of the Latham maxillary orthopedic appliance on the developing tooth buds of the infant cleft patient by Latham et al (1), Grayson and Santiago (7)

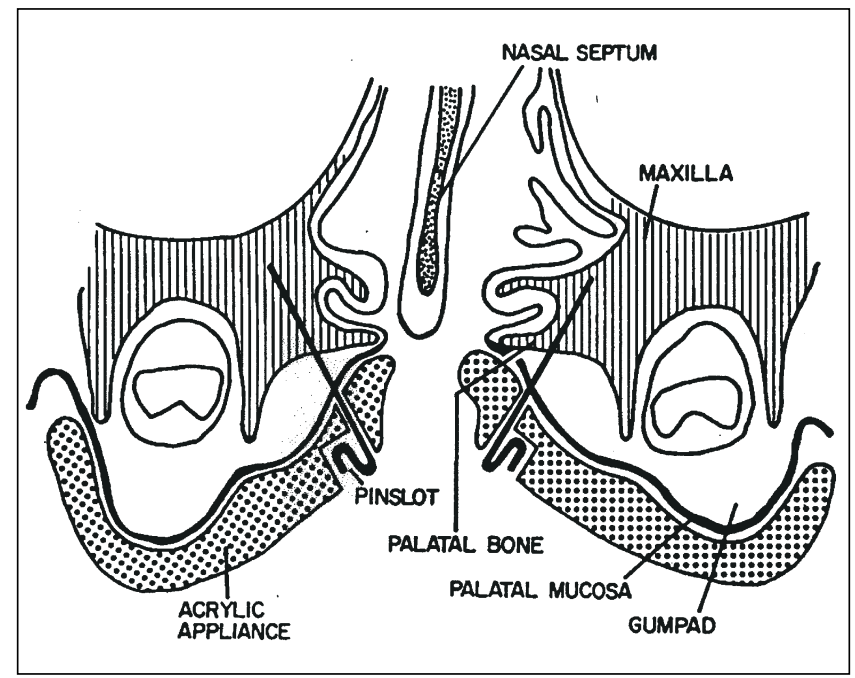

Figure 11) Stainless steel pins stabalize the Latham appliance

and others. In this series of 15 patients with a mean follow-up of 9.5 years there were no instances of tooth damage or loss attributable to the pins.

One of the advantages of using the appliance is its immediate effect on reducing the maxillary arch collapse present in complete unilateral and bilateral clefts, thus easing the lip repair and facilitating alignment of the teeth. In addition, several surgeons, including Latham et al (1), believe that it is possible to elevate the depressed nasal alar base and lengthen the deficient columella in bilateral clefts. Although it is evident that the device provides these changes before and at the time of lip repair, it has not been shown that these are maintained in long term follow-up, or that this result differs from the results obtained without using the appliance. Larson et al (8) demonstrated in 99 subjects that these changes tended to diminish in comparison with those in patients not treated with orthopedics at two years of age. In this retrospective study, there was no long term difference in maxillary arch form or nasal alar base elevation between the groups treated with and the groups treated without maxillary orthopedic devices.

Maxillary orthopedic-treated patients can have simultaneous gingivoperiosteoplasty performed at the time of cleft lip closure because the maxillary arches are anatomically reduced. In this study, 13 of 15 Saint John patients (86\%) treated with the Latham appliance were able to have a periosteoplasty at the time of lip repair, and subsequently all 13 patients developed clinical and radiographic evidence of bony bridging at the alveolus. None of them required alveolar bone grafting. Five patients had a canine tooth erupt through the periosteoplasty-formed bone. This important finding is in agreement with that reported by Lukash et al (9), who found teeth erupting into cleft bone in many of their device-treated patients. In contrast, all patients treated in Halifax without orthopedics required bone grafting; three required secondary bone grafting during the mixed dentition.

Cancellous bone grafting from a rib in the infant years and from the iliac crest during the period of mixed dentition is 
commonly used to stabilize the maxillary dentoalveolar arch and to permit tooth eruption through bone. Alveolar bone grafting is an additional surgical procedure, with its associated risks and morbidity. Elimination of the need for bone grafting either primarily or secondarily would be a significant advance.

In the present study, measurements of nasal alar base elevation and maxillary arch collapse were not significantly different between the retrospectively compared Latham appliance group in Saint John and the nonappliance group in Halifax.

\section{CONCLUSIONS}

The Latham presurgical maxillary orthopedic appliance was used in a series of cleft palate patients with generally favourable long term results. None of the 15 patients showed any evidence of tooth damage on careful orthodontic and radiological follow-up. All patients who had a periosteoplasty did not require alveolar bone grafting, and five of them erupted a canine through periosteoplasty-formed bone. There was no significant difference regarding nasal base elevation and maxillary arch form when retrospectively compared with a matched nondevice-treated control group.

\section{REFERENCES}

1. Latham RA, Kusy RP, Georgiade NG. An extraorally activated expansion appliance for cleft palatal infants. Cleft Palate $\mathrm{J}$ 1976;13:253-61.

2. Sierra FJ, Turner C. Maxillary orthopedics in the presurgical management of infants with cleft lip and palate. Pediatr Dent 1995; 17:419-23.

3. Wood RJ, Grayson BH, Cutting CB. Gingivoperiosteoplasty and midfacial growth. Cleft Palate Craniofac J 1997;34:17-20.

4. Roberts-Harry D, Semb G, Hathorn H, Killingback N. Facial growth in patients with unilateral clefts of the lip and palate: A two-center study. Cleft Palate Craniofac J 1996;33:489-93.

5. Berkowitz S. A comparison of treatment results in complete bilateral cleft lip and palate using a conservative approach versus Millard-Latham PSOT procedure. Semin Orthod 1996;2:169-84.

6. McNeil CK. Oral and Facial Deformity. London: Pitman, 1954:81-9.

7. Grayson BH, Santiago PE. Presurgical orthopedics for cleft lip and palate. In: Aston SJ, Beasley RW, Thorne CHM, eds. Grabb \& Smith's Plastic Surgery, 5th edn. Philadelphia: Lippincott-Raven, 1997:237-44.

8. Larson M, Sallstron K-O, Larson O, McWilliam J, Ideberg M. Morphologic effect of preoperative maxillofacial orthpedics (T-traction) on the maxilla in unilateral cleft lip and palate patients. Cleft Palate Craniofac J 1993;30:29-34.

9. Lukash FN, Schwartz M, Grauer S, Tuminelli F. Dynamic cleft maxillary orthopedics and periosteoplasty: benefit or detriment? Ann Plast Surg 1998;40:321-7. 